\title{
EFFECT OF PRE HARVEST BAGGING AT 60DAF ON CHEMICAL PROPERTIES
}

\author{
OF MANGO (MANGIFERAINDICAL) CV. ALPHONSO
}

NAGAHARSHITHA DEVALLA \& HALDANKAR. P. M

Department of Horticulture, College of Agriculture, Dr. B. S. Konkan Krishi Vidyapeeth

Dapoli, Ratnagiri(District), Maharashtra, India

\begin{abstract}
The study was performed in the year 2012 from March to June in the Indo Israel plot, Department of Horticulture, College of Agriculture Dapoli, District Ratnagiri. The study comprised a randomized block design with 7 treatments, namely, $T_{1}$ - brown paper bag, $T_{2}$ - newspaper bag, $T_{3}$ - butter paper bag, $T_{4}$ - plastic bag, $T_{5}$ - muslin cloth bag, $T_{6}-$ scurting bag and $T_{7}$ - control (without bag) and 3 replications. After 60 days of fruit set, the fruits were bagged. Bagging did not significantly cause variation in the chemical parameters moisture content, acidity, TSS, reducing, non-reducing sugars and $\beta$ carotene. In addition, compared to the controls, there was improvement in the total sugars in the fruits of muslin cloth $\left(T_{5}\right)$ and scurting ( $\left.T_{6}\right)$ bags at the ripe stage. Recording the top ranking performance for non-reducing and total sugars, $T_{6}$ was found to be the best treatment. In average sensory score, top ranking performance was demonstrated by $T_{5}$ and $T_{6}$. Thus, it was concluded that the bag types has an influence on the chemical properties of mango fruit.

KEYWORDS: Alphonso, Bagging, Chemical Properties, Sensory Score\& 60DAF-60 Days After Fruit Set
\end{abstract}

Received: Mar 06, 2018; Accepted: Mar 27, 2018; Published: Apr 20, 2018; Paper Id.: IJASRAPR201831

\section{INTRODUCTION}

Being the National fruit of India and the King of fruits, mango is the most important fruit crop of India. It is known for its delicious taste, exceedingly acceptable flavour, pleasing colour and exemplary nutritive value. The single cultivar "Alphonso," locally called hapus is mainly grown in the Konkan region of Maharashtra, which is produced in almost 90 per cent area because of warm and humid climate of Konkan region. Its optimum size and shape, attractive golden yellow skin and flesh colour, exemplary flavor and good shelf quality make it preferable for export. It is also well known for both table and processing purposes (Cheema and Dani, 1934). In India, its external appearance plays an important role in considering Alphonso as the mostly consumed table fruit, obtaining premium rate in the market. Various approaches are adopted to improve the external appearance of fruit, which include bagging of fruit (one of the novel ways among various means). The process of covering individual fruit using a specially designed paper or cloth bag is referred to as bagging, thereby protecting fruits from pests, fungal infections, fruit fly attack, diseases, mechanical damage, reduces spraying of insecticides and providing an estimate of harvestable fruits per tree. Pre harvest bagging demonstrated improvement in the quality of fruits. Further, in recent years the Konkan region of Maharashtra has been experiencing unfavorable weather conditions, spoiling the external appearance of fruit, thus proving the importance of bagging. Since pre harvest bagging in Alphonso mango has prospectus, the present study was conducted to study the effect of bagging on chemical properties of mango cv. Alphonso. 


\section{MATERIALS AND METHODS}

In 2012 the experiment was conducted in the Indo Israel plot, Department of Horticulture, College of Agriculture Dapoli, Dist. Ratnagiri. The red lateritic soil of the experimental plot is known for its uniform depth and good drainage conditions and its $\mathrm{pH}$ ranged from 5.6 to 6.5 . With a minimum of $18.5^{\circ} \mathrm{C}$ and maximum of $30.8^{\circ} \mathrm{C}$ temperature, $78 \%$ humidity throughout the year and an average precipitation of 3,500 mm distributed from June to September, Dapoli possesses a more or less tropical climate. The experiment followed a randomized block design, with each treatment replicated thrice, comprising 20 fruits per treatment per replication. Treatment details are as follows: $\mathrm{T}_{1}$ - brown paper bag, $\mathrm{T}_{2^{-}}$newspaper bag, $\mathrm{T}_{3^{-}}$butter paper bag, $\mathrm{T}_{4^{-}}$plastic bag, $\mathrm{T}_{5^{-}}$muslin cloth bag, $\mathrm{T}_{6^{-}}$scurting bag and $\mathrm{T}_{7^{-}}$control. On all bags, except scurting and muslin cloth bags, perforations were made so that they obtain proper ventilation for fruit development. For bagging, fruits of egg size were selected. If a cluster has more than two fruits, the smaller underdeveloped, deformed, spotted fruits are removed by sector and 1-2 healthy fruits were considered for bagging. After bagging in the brown paper bags, newspaper bags, butter paper bags and plastic bags, the bags were stapled carefully, to stop the fruits from the bag and also to avoid open space for entry of insects or rain, etc. On the other hand, the scurting and muslin cloth bags were tied with the help of thread. Their chemical parameters were observed at harvest and the ripe stages of fruits and the sensory score recorded at ripe stage. To determine the fruit chemical composition (moisture content, TSS, acidity, ascorbic acid, $\beta$ carotene, reducing, non-reducing and total sugars)at harvest and ripe stages, according to A.O.A.C (1975), $\mathrm{T}_{4}$ fruits were selected randomly and analyzed. Per the method suggested by Panse and Sukhatme (1985), the data obtained were statistically analyzed. The standard error of mean (SEM) was calculated, and when the results were found to be significant the critical difference (C.D.) was arrived at 5 per cent.

\section{RESULTS AND DISCUSSIONS}

Table 1 shows the chemical parameters, which demonstrates that bagging doesn't affect the moisture content at harvest and ripe stages. The highest moisture content $(82.10 \%)$ was observed in $\mathrm{T}_{4}$ fruits, whereas the lowest $(80.46 \%)$ was observed in $\mathrm{T}_{2}$ fruits, and at ripe stage the highest moisture content (81.00\%) was observed in $\mathrm{T}_{6}$ fruits and the lowest (79.10\%)in $\mathrm{T}_{2}$ fruits. The quality of fruits is affected by light (Anon, 2005). In mango fruits, these results are in line with the results of Ding and Syakirah (2010). Because of bagging the TSS did not show significant variation at harvest and at ripe stages. The highest TSS was observed in $\mathrm{T}_{7}\left(8.37^{0} \mathrm{~B}\right)$ and the lowest was observed in $\mathrm{T}_{2}(8.170 \mathrm{~B})$ at harvest. The highest TSS was noticed in $\mathrm{T}_{2}\left(15.96^{\circ} \mathrm{B}\right)$ and the lowest was noticed in $\mathrm{T}_{1}\left(14.64^{0} \mathrm{~B}\right)$ at ripe stage. Both at harvest and ripe stages, the acidity (\%) of alphonso mango fruits did not show significant variation between treatments. At harvest, the highest acidity (\%) was observed $\operatorname{int}_{3}(3.69 \%)$ and the lowest in $\mathrm{T}_{7}(3.61 \%)$. At ripe stage, the highest acidity (\%) was noticed in $\mathrm{T}_{2}(0.41 \%)$ and the lowest was recorded in $\mathrm{T}_{5}(0.38 \%)$. Ascorbic acid at harvest showed significant variation being the highest in $_{4}(79.43 \mathrm{mg} / 100 \mathrm{~g})$, which was significantly superior to all other treatments, and the lowest was noticed in $\mathrm{T}_{2}(78.11 \mathrm{mg} / 100 \mathrm{~g})$. Between treatments, no significant variation in ascorbic acid content was observed at ripe stage. $\mathrm{T}_{6}$ indicated the highest ascorbic acid content $(54.90 \mathrm{mg} / 100 \mathrm{~g})$, and both in $\mathrm{T}_{2}$ and $\mathrm{T}_{4}$ demonstrated the lowest ascorbic acid content (52 mg /100 g). At harvest stage, reducing sugars varied significantly at the harvest stage. $\mathrm{T}_{7} \mathrm{had}_{\mathrm{g}}$ highest reducing sugars $(1.88 \%)$. $\mathrm{T}_{2}$ showed the lowest reducing sugars $(1.80 \%)$. In the ripe stage, the reducing sugars showed no significant variation between treatments. Both $\mathrm{T}_{6}(3.95 \%)$ and $\mathrm{T}_{7}(3.95 \%)$ demonstrated the highest reducing sugars, and $\mathrm{T}_{1}(3.82 \%)$ showed the lowest reducing sugars. According to Harhash and Al-obeed (2010), the highest reducing sugar was in bluebag $(27.69 \%)$ in date palm compared to control $(23.33 \%)$. At harvest stage, non-reducing 
sugars varied significantly due to bagging. The non-reducing sugars (\%) were the highest in $\mathrm{T}_{6}(1.21 \%)$ and the lowest in $\mathrm{T}_{1}(1.08 \%)$ at the harvest stage. At ripe stage, there was no significant variation in non-reducing sugars. Both $\mathrm{T}_{5}$ and $\mathrm{T}_{6}$ (10.32\%) demonstrated the highest non-reducing sugars and the lowest in $\mathrm{T}_{1}(9.98 \%)$. According to Harhash and AlObeed (2010), the highest non-reducing sugars (33.95\%) was in observed in the date palm fruit bagged with blue paper bag compared to control (30.67\%). The total sugar varied significantly both in the harvest and ripe stages. In $\mathrm{T}_{5}$, $\mathrm{T}_{6}$, and $\mathrm{T}_{7}(3.07 \%)$ total sugar was the highest in the harvest stage. In $\mathrm{T}_{1}$ and $\mathrm{T}_{2}(2.9 \%)$, reducing sugar was lowest in $\mathrm{T}_{6}$ (14.27\%), the total sugar in the ripe stag was highest, butin $\mathrm{T}_{1}(13.80 \%)$ it was lowest. As mentioned by Harhash and Alobeed (2010), the date palm fruit in blue bag demonstrated the highest total sugars (61.64\%) compared to the control (54 $\%) . \beta$ carotene varied significantly in the harvest stage. In $\mathrm{T}_{4}(318.73 \mu \mathrm{g}), \beta$ carotene was highest and in $\mathrm{T}_{2}(303.63 \mu \mathrm{g})$ the lowest. The variation in $\beta$ carotene was not significant between treatments in the ripe stage. In $_{7}(11880 \mu \mathrm{g}), \beta$ carotene was highest but in $\mathrm{T}_{2}(11114.67 \mu \mathrm{g}), \beta$ carotene was lowest.

\section{REFERENCES}

1. A.O.A.C., (1975).Official Methods of Analysis. Association of Official Analytical Chemists. 12 th Edition, Washington, D. C. 20044.

2. Anonymous, (2005). A text book of fruit production, Aman Publishing House, meerut-250002, Pp. 8.

3. Cheema, G. S. and P. C. Dani (1934). Report on the export of mangoes to Europe, Dept. of Agril., Bombay Bull. No. 170.

4. Ding, P. and M. N. Syakirah (2010). Influence of fruit bagging on post harvest quality of 'Haruminus' mango. Acta Horticulturae, 877: 169-174.

5. Sanjay, Kumar, et al. "Extent of physical post harvest losses of important vegetables of Varanasi in Uttar Pradesh."International Journal of Agricultural Science and Research (IJASR) 5.5 (2015): 139-145.

6. Harhash, M. M. and R. S. Al-Obeed (2010).Effect of Bunch Bagging Color on Yield and Fruit Quality of Date Palm. American-Eurasian J. Agric. \&amp; Environ. Sci., 7(3): 312-319.

7. Panse, V. G. and P. V. Sukhatme (1985).Statistical methods for Agricultural Workers. ICAR

8. Rev. Ed. By Sukhatme, P. V. and Amble, V. N. pp. 97-156. 
